\title{
COMUNICACIÓN EFECTIVA EN ENTORNOS EMPRESARIALES
}

Lina Calle Arango ～～Lina García Rodríguez

Javier H. Murillo Ospina

ado empatía

roponga un plan a seguir. Esta estructura (orden discursivo) es usada en la narrativa del cine ue recurre a ella para cautivar la atención del público de principio a fin. Filmes de grar cogida, como Rocky o Maléfica, por dar solamente dos ejemplos, inician la historia con la ificultades en las que se encuentra el protagonista; después, narran cómo este supera retos bstáculos para llegar a una gran cúspide, el punto máximo de superación de la situació anar, vencer, conseguir el resultado soñado...). Tras el triunfo, se cierra con una moralej inal, que constituye la acción que se espera que tome el receptor. Al aplicar esta estructura e contexto empresarial se obtienen los mismos resultados. En la narración de los problemas empleados logran comprender el esfuerzo que le ha tomado a la empresa superar lo roblemas iniciales, y se solidariza con ella; en la segunda parte, siente orgullo y satisfacció uando ve los obstáculos que la empresa ha superado; y en la tercera parte, se apropia de 1 noraleja final que busca una acción, es decir, un compromiso de los empleados con alg ropuesto por la organización. Esta estructura debería llevar a un aumento en la confianz tre empleados y líderes, que resulta ser un elemento no solo difícil de lograr sino, sobr do, escaso dentro de las organizaciones (Kotter, 1999). Es así como puede resultar más fác e comprender el proceso que una organización ha tenido y las razones por las que ha asumi o ciertas directrices o decisiones, y no otras. Al respecto, Kotter (1999, p. 48) explica que stamente, un "[...] motivo común de resistencia al cambio es que los empleados no ven la 


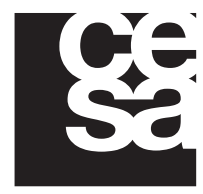

Colegio de Estudios

Superiores de Administración 



\title{
COMUNICACIÓN EFECTIVA EN ENTORNOS EMPRESARIALES
}

\author{
Lina Calle Arango \\ Lina García Rodríguez \\ Javier H. Murillo Ospina
}

CESA - Colegio de Estudios Superiores de Administración 
658.45/ M977c 2017

Murillo O, Javier $\mathrm{H}$

Comunicación efectiva en entornos empresariales / Javier H. Murillo O. ; Lina García R. ; Lina Calle A. Colombia, Editorial CESA 2017. 160p.

DESCRIPTORES:

1.COMUNICACIÓN EN ADMINISTRACIÓN- Estrategia y técnicas 2.COMUNICACIÓN ORGANIZACIONAL - Estrategia y técnicas 3.COMUNICACIÓN ORAL - Metodología 4. HABLAR EN PÚBLICO 5. ANÁLISIS DEL DISCURSO

(C) 2017 CESA - Colegio de Estudios Superiores de Administración

(C) 2017 Lina Calle Arango

(C) 2017 Lina García Rodríguez

(C) 2017 Javier H. Murillo Ospina

ISBN Impreso: 978-958-8988-16-0

ISBN Digital: 978-958-8988-17-7

\section{Editorial CESA}

Casa Incolda

Diagonal 34a No 5a- 23

www.editorialcesa.com

www.cesa.edu.co

editorialcesa@cesa.edu.co

Grupo de Estudios en Administración

Proyecto: Pautas para escribir más fácil y correctamente la lengua española

Código interno: 50003

Bogotá, D.C, julio de 2017

Dirección: Editorial CESA

Corrección de estilo: Silvia Garavito Constantín

Diseño y diagramación: Damaris Martínez

Impresión: Imageprinting Ltda

Todos los derechos reservados. Esta obra no puede ser reproducida sin el permiso previo escrito.

Impreso y hecho en Colombia

Printed and made in Colombia 


\section{CONTENIDO}

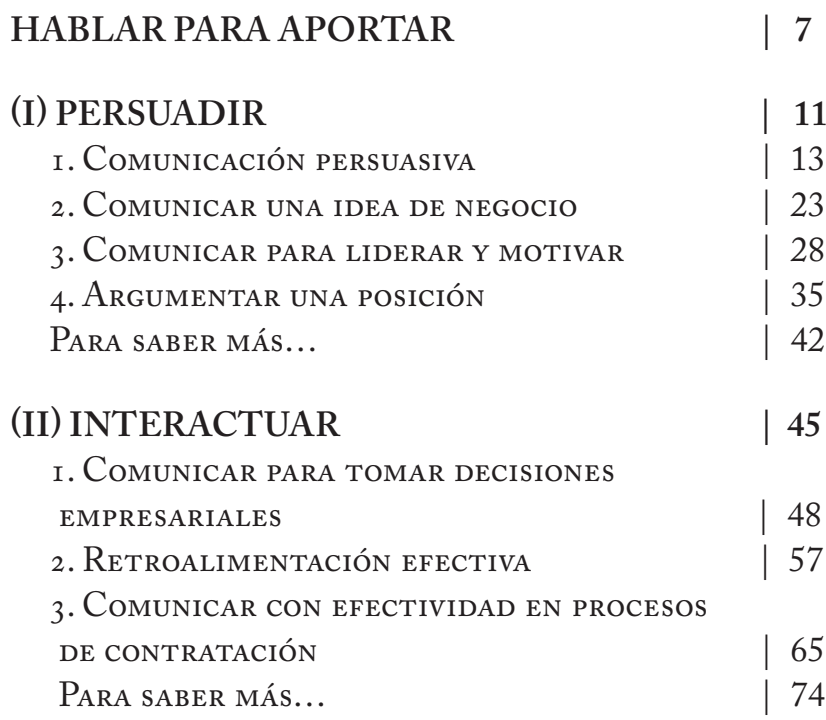

(III) RECOMENDACIONES COMPLEMENTARIAS

I. RESPONDER A PREGUNTAS DIFÍCILES

2. HACER DE LA VOZ UN ALIADO

3. MOSTRAR PARA APORTAR

Para saber más...

\section{(IV) PUESTA EN PRÁCTICA}

I. PRESENTACIÓN DE UNA IDEA DE NEGOCIO

2. LIDERAZGO Y MOTIVACIÓN

3. ARGUMENTAR UNA POSICIÓN

4. TOMA DE DECISIONES EMPRESARIALES

5. RETROALIMENTACIÓN

136

6. PROCESO DE CONTRATACIÓN 



\section{HABLAR PARA APORTAR}

uien hace un informe, participa en una reunión o realiza una conferencia, ¿piensa más en cómo se verá, personalmente, que en el aporte que lo que comunica implica para el otro? Si es así, su comunicación, además de impedirle avanzar, puede estar afectando negativamente su credibilidad.

El propósito de este libro es procurar la mejora de las habilidades de comunicación de sus lectores. Para hacerlo, propone estrategias efectivas de comunicación en entornos empresariales que deberían permitirle a estudiantes, docentes y profesionales mejorar su comunicación y, por lo tanto, generar mayor confianza y credibilidad en su interlocutor.

Se parte del hecho de que, como lo propone Escandell, la finalidad fundamental de la comunicación es alcanzar objetivos con otras personas; en este sentido, se habla con intención (Escandell Vidal, 1996). Por esto, para mejorar las interacciones comunicativas, resulta imprescindible que aportar sea la primera motivación al hablar o escribir. Queda claro que hablar para aportar significa pensar en el otro antes que en sí mismo; proponer, en cualquier contexto, información que le sea de utilidad a quien escucha, y que le permita avanzar en la solución de las tareas e inconvenientes que surgen cotidianamente. 
A lo largo de este libro, el lector -un estudiante, un docente o un profesional- encontrará diferentes estrategias para seleccionar, ordenar y transmitir sus ideas; todo con el fin de lograr mayor efectividad de su comunicación en diferentes situaciones del ámbito empresarial, tanto de forma oral como escrita.

Es común pensar que la primera diferencia entre la oralidad y la escritura radica en que la primera es espontánea y la segunda formal, en tanto que los usuarios de la lengua se comunican oralmente todos los días y en diversos escenarios. Por ello, muchas veces no se le atribuye la importancia suficiente a la formalización de la comunicación oral. Sin embargo, muchas manifestaciones comunicativas orales no son espontáneas (aunque a veces lo parezcan); la mayoría de conferencias, discursos o presentaciones públicas requieren de una ardua preparación y puesta en práctica, así como de apoyo de las formas escritas. Dominar el arte de la oratoria significa articular los procesos de pensamiento con una buena dosis de trabajo y de práctica.

La primera parte del libro propone las metodologías que le ayudarán al lector a seleccionar, a organizar y a transferir las ideas que se desean presentar en función del objetivo de comunicación en diferentes situaciones empresariales. A su vez, estas metodologías ayudarán al perfeccionamiento de sus habilidades comunicativas, en tanto que le facilitarán la construcción de los mensajes y le aportarán mayor seguridad para transmitir sus ideas.

En la segunda parte se busca desarrollar una conciencia del diálogo en entornos laborales y empresariales como acto comunicativo a partir del cual se busca construir cuatro actitudes: i) capacidad de síntesis; ii) capacidad de escucha para responder; iii) comprender al otro y valorar su posición; iv) capacidad para generar avance.

Es claro que en entornos empresariales, así como en otro tipo de escenarios en los que negociar es parte fundamental del acto comunicativo, la persuasión constituye un pilar fundamental. Si bien 
construir discursos claros y valiosos resulta determinante para persuadir, el mensaje resulta tener, en los casos de oralidad, una pequeña parte del impacto. Así lo demuestra la investigación realizada por Albert Meharabian (1971), psicólogo emérito de la Universidad de Los Ángeles, que arroja que el mensaje tiene solo el 7\% del impacto en el interlocutor, mientras que la comunicación no verbal (cuerpo y voz) tiene el 93\%. Esto lleva justamente a la tercera parte del libro, en la cual se incluyen algunas recomendaciones para generar coherencia entre su mensaje y su comunicación no verbal -que incluye los elementos corporales y la presentación visual-, así como el uso de la voz.

La última parte es más práctica que teórica. En ella el lector encontrará un robusto paquete de ejercicios que le permitirán poner en práctica los conceptos que se trabajaron a lo largo del libro; actividades que podrán ser adaptadas a diferentes tipos de grupos y de niveles de experiencia en el entorno empresarial.

Esperamos que este texto sea tan sencillo de usar y tan efectivo para sus lectores como grato fue para nosotros estructurarlo y escribirlo. 
CESA-Colegio de Estudios Superiores de Administración. Este libro se terminó de imprimir en julio de 2017, en Bogotá DC. Se compuso en caracteres Adobe Caslon Pro de 12 pts. y se imprimió sobre papel bond blanco de $75 \mathrm{gr}$. 